Acta Universitatis Wratislaviensis No 3888

PRAWO CCCXXVII

Wrocław 2019

DOI: $10.19195 / 0524-4544.327 .19$

\author{
SERGEY N. POTAPKIN \\ ORCID: 0000-0003-3920-6295
}

Всероссийский государственный университет юстиции criminallaw_svf@mail.ru

\title{
Реабилитация нацизма как проявление экстремизма: вопросы квалификации по уголовному и административному праву Российской Федерации
}

\begin{abstract}
Резюме: Статья посвящена вопросам квалификации действий, связанных с реабилитацией нацизма по УК РФ, как проявлений экстремизма. Рассматриваются вопросы становления практики применения ст. 354.1 УК РФ, отграничения реабилитации нацизма от смежных преступлений и административных правонарушений.
\end{abstract}

Ключевые слова: экстремистская деятельность, террористическая организация, экстремистская организация, нацизм, реабилитация нацизма.

Уголовный кодекс Российской Федерации 1996 г. (далее — УК РФ) в действующей редакции предусматривает ответственность за различные проявления экстремистской деятельности. Помимо того, что предусматривается отдельно уголовная ответственность за организацию и деятельность экстремистской организации, экстремистского сообщества, террористической организации, террористического сообщества, самостоятельной уголовно-правовой оценке подлежат общественно-опасные действия, которые совершают участники соответствующих формирований.

В последнее время одним из проявлений экстремизма стало использование лицами нацистской идеологии. Нацизм как идеология обосновывает превосходство одной человеческой расы, нации над другой. Логическим продолжением такой постановки вопроса являются действия адептов данной 
идеологии, которые направлены на физическое устранение представителей других рас и национальностей.

Федеральным законом от 5.05.2014 г. № 128-Ф3 УК РФ был дополнен ст. 354.1 УК РФ «Реабилитация нацизма».

Поскольку нацизм является одним из проявлений экстремизма, то деятельность нацистских организаций в РФ может быть запрещена в судебном порядке в силу их признания экстремистскими ${ }^{1}$ или террористическими ${ }^{2}$.

Среди запрещенных в РФ террористических и экстремистских организаций можно выделить те, которые можно было бы назвать нацистскими.

Среди запрещенных террористических организаций часть организована по религиозному признаку, часть - по территориальному признаку, часть по идеологическому признаку (в том числе нацистскому), а в ряде случаев имеет место смешение признаков. Примерно те же критерии используются и при создании организаций, признанных экстремистскими.

Однако, очевидно, что организаций, в основе деятельности которых преобладает идеология нацистского толка, больше среди экстремистских организаций. На это, в частности, может указывать наличие в названии соответствующей организации, что эта организация «национальная», или указывается конкретная национальность участников соответствующей группы, хотя это и не является обязательным. Например, суд, признавая организацию - межрегиональное национал-радикальное объединение «Misanthropic division $»^{3}$, - экстремистской организацией, и запрещая ее деятельность на территории Российской Федерации, указал:

...Пропагандистскую деятельность «Misanthropic division» осуществляет посредством информационно-телекоммуникационной сети Интернет, где активно освещает идеологию, направленную на пропаганду идей расизма и насилия, сепаратистских и революционных настроений среди молодежи, а также популяризации украинских национал-радикализованных формирований и вооруженных формирований Украины («Правый сектор», полк «Азов»)

1 Перечень некоммерческих организаций, в отношении которых судом принято вступившее в законную силу решение о ликвидации или запрете деятельности по основаниям, предусмотренным Ф3 «О противодействии экстремистской деятельности». Министерство юстиции Российской Федерации, http://minjust.ru/nko/perechen_zapret (дата обращения: 1.12.2017).

2 Единый федеральный список организаций, в том числе иностранных и международных организаций, признанных в соответствии с законодательством Российской Федерации террористическими. Федеральная служба безопасности Российской Федерации. (Edinyj federal'nyj spisok organizacij, v tom čisle inostrannyh i meždunarodnyh organizacij, priznannyh v sootvetstvii s zakonodatel'stvom Rossijskoj Federacii terrorističeskimi. Federal'naâ služba bezopasnosti Rossijskoj Federacii) http://www.fsb.ru/fsb/npd/terror.htm (дата обращения: 1.12.2017).

3 Название данной организации на русском языке «Мизантропик дивижн». Сокращенно она имеутся также «MD», «Md».

4 Гражданское дело № 3-129/2015, Архив Красноярского краевого суда. 2015 г. (Graždanskoe delo № 3-129/2015, Arhiv Krasnoârskogo kraevogo suda. 2015 g.).

Prawo 327, 2019

(C) for this edition by CNS 
Очевидно, что организации националистического толка более опасны, чем отдельные физические лица, поддерживающие идеологию нацизма. Однако это не означает, что наказуема деятельность граждан, только объединившихся в группу по национальному признаку и исповедующих идеологию нацизма.

После дополнения УК РФ 1996 г. статьей 354.1 «Реабилитация нацизма» стало возможным привлекать к уголовной ответственности за соответствующие действия и отдельных граждан, не объединенных в группы.

Диспозиция ч. 1 ст. 354.1 УК РФ предусматривает ответственность «за отрицание фактов, установленных приговором Международного военного трибунала для суда и наказания главных военных преступников европейских стран оси, одобрение преступлений, установленных указанным приговором, а равно распространение заведомо ложных сведений о деятельности СССР в годы Второй мировой войны, совершенные публично», а ч. 3 ст. 354.1 УК РФ «распространение выражающих явное неуважение к обществу сведений о днях воинской славы и памятных датах России, связанных с защитой Отечества, а равно осквернение символов воинской славы России, совершенные публично».

Непосредственно из текста статьи 354.1 УК РФ не усматривается, каким образом (способом) должны быть совершены указанные действия, хотя указано, что они совершаются публично. В связи с тем, что время действия ст. 354.1 УК РФ относительно незначительно, отсутствует многочисленная практика ее применения.

Очевидно, что нанесение изображения свастики на тело не может образовывать состав преступления, предусмотренного ст. 354.1 УК РФ. Кроме того, подобные «наколки» в недавнем прошлом имели совершенно другое значение среди лиц, отбывающих наказание в виде лишения свободы, где свастика на плече означала принадлежность к группе осужденных, отрицающих установленные правила отбывания наказания в исправительном учреждении, придерживающихся неподчинения требованиям администрации исправительного учреждения («отрицалово»).

Кроме того, необходимость изображения нацистских символов практически всегда возникает в процессе съемки кинофильмов о Великой Отечественной войне 1941-1945 гг. и о Второй Мировой войне 1939-1945 гг. Необходимость копирования соответствующих материалов имеет место в ходе оперативно-розыскной деятельности и последующих после возбуждения уголовного дела следственных действий, направленных на обнаружение и фиксацию следов преступления, предусмотренного ст. 354.1 УК РФ.

Поэтому всегда важно установить обстоятельства произошедшего, контекст поступка лица, какую цель оно преследует.

Определенную сложность в установлении субъективной стороны преступления может представлять то, что лицо может не ассоциировать кон- 
кретные символы с идеологией нацизма в силу собственной безграмотности. Например, та же самая свастика была заимствована нацистами у древних славян, где она означала «коловорот» или «черное солнце». Кроме того, какие-то руны, также заимствованные нацистами, например, «волчий крюк», кому-то могут просто понравиться за внешний вид. Во избежание недоразумений было бы правильным нормативно в постановлении Правительства РФ предусмотреть перечень и словесное описание символов нацизма для нужд применения ст. 354.1 УК РФ.

С учетом этого первостепенное значение для правильной квалификации приобретают комментарии, прилагающиеся к соответствующим изображениям, которые лицо либо само сочинило, либо скопировало где-то, в том числе вместе с соответствующей картинкой.

Среди встречающихся обвинительных приговоров по ст. 354.1 УК РФ обращает на себя внимание то, что практически везде встречается использование сети «Интернет». Например, суд установил реабилитацию нацизма в следующих действиях:

...придерживаясь идеологии германского нацизма, сформировав в себе одобрительное отношение к войскам «СС» (охранные отряды национал-социалистической рабочей партии Германии, общеизвестные под названием «СС»), которые приговором Международного военного трибунала для суда и наказания главных военных преступников европейских стран оси от ДД.ММ.ГГГГ объявлены преступной организацией в связи с участием в военных преступлениях и преступлениях против человечности, связанных с войной, в связи с тем, что «СС» использовалась для целей, которые, являются преступными и включают преследование и истребление евреев, зверства и убийства в концентрационных лагерях, эксцессы, совершавшиеся при управлении оккупированными территориями, проведении в жизнь программы использования рабского труда и жестокое обращение с военнопленными и их убийства, подсудимый С.П. действуя умышленно, публично, с целью реабилитации нацизма путем одобрения преступлений, установленных приговором Международного военного трибунала для суда и наказания главных военных преступников европейских стран оси, осознавая фактический характер и общественную опасность своих преступных действий, разместил ДД.ММ.ГГГГ текст, совмещенный с фотографическим изображением немецких солдат в форменной одежде периода Второй мировой войны и заголовком «15 боевых правил SS...» и ДД.ММ.ГГГГ разместил текст, совмещенный с фотографическим изображением в виде стилизованных эмблем подразделений ряда частей войск «СС» и немецкой свастики, с указанием количественных показателей и заголовком «Немного сведений о том, сколько воевало русских на стороне Германии. Как говорится: «Спасибо деду за попытку!» которые согласно заключению психолого-лингвистической экспертизы содержат лингвистические и психологические признаки оправдания (одобрения) деятельности частей войск «СС», действий воинских и специальных подразделений фашистской Германии в период Второй мировой войны, в том числе, оправдание действий (боевые действий, участие в войне) подразделений, сформированных по национальному признаку и принимавших участие на стороне гитлеровской Германии в борьбе с Красной Армией и ее союзниками.

Таким образом, С.П., действуя умышленно, разместил на своей странице в социальной сети «Вконтакте», открытой для публичного доступа другим пользователям социальной сети, тексты, совмещенные с изображениям и комментариями, содержащие одобрение деятельности войск «СС», которые приговором Международного военного трибунала для суда и наказания главных военных преступников европейских стран оси объявлены пре-

Prawo 327, 2019

(C) for this edition by CNS 
ступной организацией в связи с участием в военных преступлениях и преступлениях против человечности, связанных с войной ${ }^{5}$.

Одновременно суд также усмотрел в действиях виновного лица состав преступления, предусмотренный ч. 1 ст. 282 УК РФ «Возбуждение ненависти либо вражды, а равно унижение человеческого достоинства».

В другом случае суд выявил признаки реабилитации нацизма в том, что

...придерживаясь идеологии германского нацизма, публично, с целью реабилитации нацизма, разместил текст с заголовком: «Миф о том, что Гитлер хотел убить всех славян», в котором содержатся лингвистические и психологические признаки оправдания идеологии фашизма (нацизма), а также отрицание фактов, установленных приговором Международного военного трибунала для суда и наказания главных военных преступников европейских стран оси ${ }^{6}$.

Подобным образом происходит становление практики применения ст. 354.1 УК РФ не только в Крыму, но и в других регионах РФ. Например, суд определил:

...в январе 2015 года в «Гвардейском парке» в г. Красноярске на установленных в нем монументах в память о героях Великой Отечественной войны, лицами, разделяющими идеологию «Md», осуществлена акция вандализма, выраженная в осквернении символов воинской славы России путем нанесения нацистской символики и надписей: «ДНР гори в огне», «Украина мы с тобой (6 символов свастики по кругу)», «Героям слава», «Смерть коммунистам!», «88 «Сдвоенная руна-знак “СС”», «Слава Украине». Также на монументы нанесено изображение национального флага Украины. По указанному факту следственным отделом по Советскому району г. Красноярска Главного следственного управления Следственного комитета России по Красноярскому краю и Главным следственным управлением Следственного комитета России по Красноярскому краю возбуждены уголовные дела по ч. 3 ст. 354.1 УК РФ «Реабилитация нацизма», ч. 1 ст. 282 УК РФ «Возбуждение ненависти либо вражды, а равно унижение человеческого достоинства», которые соединены в одно производство... В соответствии с результатами комплексной психолого-лингвистической судебной экспертизы материалов уголовного дела № 25029075 установлено, что надписи и изображения, нанесенные на скульптурные изображения, распознающиеся как посвященные теме Великой отечественной войны (1941-1945 гг.), идеологически, семантически противопоставлены этим символам. Размещение в публичном общественном пространстве указанных надписей и нацистской символики является актами эпатажа, а также декларации и пропаганды идеологии войны, насилия, идеологии нацизма, пропаганды политических организаций. Как отмечено экспертами, в представленных материалах содержится информация, способная возбудить ненависть, вражду по признаку принадлежности к социальной группе, а также пропаганда нацистской символики ${ }^{7}$.

При этом на практике встречаются случаи совершения преступления, предусмотренного ч. 1 ст. 354.1 УК РФ и без совокупности со ст. 282 УК РФ,

5 Уголовное дело № 1-25/2015, Архив Верховного Суда Республики Крым. 2015 г. (Ugolovnoe delo № 1-25/2015, Arhiv Verhovnogo Suda Respubliki Krym. 2015 g.).

6 Уголовное дело № от 2.08.2017 по делу № 1-18/2017, Архив Верховного Суда Республики Крым. 2017 г. (Ugolovnoe delo № ot 2.08.2017 po delu № 1-18/2017, Arhiv Verhovnogo Suda Respubliki Krym. 2017 g.).

7 Гражданское дело № 3-129/2015, Архив Красноярского краевого суда. 2015 г. (Graždanskoe delo № 3-129/2015, Arhiv Krasnoârskogo kraevogo suda. 2015 g.).

Prawo 327, 2019

(C) for this edition by CNS 
когда в действиях виновных суд не усматривает призывов к уничтожению лиц другой национальности, веры или расы. Так, суд установил:

...[подсудимый] публично, для обозрения неограниченного круга лиц, разместил фотоизображение политических деятелей, имеющих внешнее сходство с М. и А. Гитлером, одетых в военную форму германской армии времен Второй мировой войны, с изображением на форменной рубашке А. Гитлера нацисткой символики (свастики) в виде креста с загнутыми под прямым углом концами, прокомментировав его выражением следующего содержания: “приближается непонятный праздник 23 февраля, куда более подходящими днями для праздника являются 01 сентября, потому что 01 сентября 1939 года нацистская Германия напала на Польшу и началась война или например 22 июня, потому что 22 июня 1941 года войска Рейха напали на СССР. Так давайте же праздновать столь знаменательные дни!!! Гитлер хотя бы попытался изменить мир к лучшему». Тем самым указанным комментарием П. одобрил начало Второй мировой войны, то есть вторжение германских войск 1 сентября 1939 года на территорию Польши и начало Великой Отечественной войны, то есть вторжение на территорию СССР 22 июня 1941 года, что согласно приговору Международного военного трибунала для суда и наказания главных военных преступников европейских стран оси, признано актом явной агрессии и преступлением ${ }^{8}$.

Встречается также и практика применения ч. 3 ст. 354.1 УК РФ. Например, суд установил, что действия подсудимого проявляют

...презрение к празднику «9 мая - День Победы советского народа в Великой Отечественной войне 1941-1945 годов (1945 год)», который в соответствии со ст. 1 Федерального закона «О днях воинской славы и памятных датах России» № Ф3-32 от 13.03.1995 является днем воинской славы России, связанным с защитой Отечества», указав, что он «...умышленно разместил, тем самым, представив содержание неопределенному кругу лиц из числа зарегистрированных пользователей социальной сети “Вконтакте” для публичного обозрения следующие изображения:

1. 9 мая 2015 года — изображение наградного знака нацистской Германии с крюкообразным правосторонним крестом и надписью “1939” на фоне орденской ленты, сопровождавшееся надписью: “Помним! Гордимся!”, представляющее из себя стилизацию поздравления и являющееся выражением положительного отношения к действиям нацисткой Германии;

2. 11 мая 2015 года - изображение красного флага на пересечении черно-белых лент в белом круге с изображением правостороннего крюкообразного креста на темном фоне, сопровождающееся текстом “9 мая посвящается никакой капитуляции!!! HeilHitler!”, а также двумя надписями на фоне лент черно-оранжевого и черно-белого цветов: “Мне не нужна ваша ленточка! У меня есть своя...” и “AdolfHitler!”, выражающее поддержку нацизма через противопоставление георгиевской ленте флагу нацистской Германии;

3. 11 мая 2015 года - изображение А. Гитлера на темном фоне, сопровождающееся надписью “Мне п*й кто у тебя там воевал”, содержащее негативную информацию о 9 мая в неприличной форме» 9 .

При производстве по уголовным делам данной категории стало практически обязательным закреплять полученные доказательства путем проведения лингвистической и психологической экспертиз.

8 Уголовное дело № 2-34/2016, Архив Ставропольского краевого суда. 2016 г. (Ugolovnoe delo № 2-34/2016, Arhiv Stavropol'skogo kraevogo suda. 2016 g.).

9 Уголовное дело № 1-34/2016, Архив Верховного суда Республики Бурятия. 2016 г. (Ugolovnoe delo № 1-34/2016, Arhiv Verhovnogo suda Respubliki Burâtiâ. 2016 g.).

Prawo 327, 2019

(C) for this edition by CNS 
Проблемы применения ст. 354.1 УК РФ во многом связаны с тем, что нередко действия, которые могли бы быть квалифицированы по данной статье УК РФ, ранее квалифицировались только по ст. 282 УК РФ. Отчасти это понятно, т. к. ст. 282 УК РФ предусматривает ответственность «за возбуждение ненависти либо вражды, а также за унижение достоинства человека либо группы лиц по признакам пола, расы, национальности, языка, происхождения, отношения к религии, а равно принадлежности к какой-либо социальной группе, совершенные публично или с использованием средств массовой информации либо информационно-телекоммуникационных сетей, в том числе сети “Интернет”».

Таким образом, данные преступления схожи по публичному характеру совершения и тому, что в обоих случаях мотивация может быть связана с уничижительным отношением к людям по признакам расы или национальности. Именно при подобном способе совершения преступления с учетом конкретного содержания представляется возможным ставить вопрос не о конкуренции, а о совокупности ст. 282 и ст. 354.1 УК РФ.

Также во избежание риска последующего оправдания и ухудшения статистической отчетности на практике нередко похожие ситуации квалифицируются по КоАП РФ, исходя из того, что «лучше синица в руке, чем журавль в небе», где синица - это постановление по административному делу, а журавль - это приговор по уголовному делу.

Как правило, в этом случае традиционно применяется ст. 20.3 КоАП РФ, которая предусматривает административную ответственность за пропаганду либо публичное демонстрирование нацистской атрибутики или символики, либо атрибутики или символики экстремистских организаций, либо иных атрибутики или символики, пропаганда либо публичное демонстрирование которых запрещены федеральными законами.

Так сложилось, что суды традиционно расценивали поступки, связанные с демонстрацией нацистской символики, как административные правонарушения Например, суд установил, что

...на заднем стекле автомашины ... наклеенный восьмилучевой коловрат, который согласно акту исследования от ДД.ММ.ГГГГ, относится к сходным со свастикой до степени смешения и в таком своем качестве подлежит идентификации как, знак, реабилитирующий и героизирующий нацизм. В судебном заседании Т.М.А. вину не признал и пояснил, что он сам сделал и наклеил данный знак, как оберегающий, поскольку является старовером. Судья, выслушав Т.М.А., не заявившего какие-либо ходатайства, изучив материалы дела, полагает, что в действиях Т.М.А. усматриваются признаки правонарушения, предусмотренные ст. 20.3. ч. 1 КоАП РФ - пропаганда либо публичное демонстрирование атрибутики или символики, сходных с нацистской атрибутикой или символикой до степени смешения... ${ }^{10}$

10 Административное дело № 5-493/2014, Архив Лаишевского районного суда Республики Татарстан. 2014 г. (Administrativnoe delo № 5-493/2014, Arhiv Laiševskogo rajonnogo suda Respubliki Tatarstan. 2014 g.).

Prawo 327, 2019

(C) for this edition by CNS 


\section{В другом случае, суд установил, что}

...ФИО6 --.--.---- г. на своей странице в сети интернет на $\mathrm{N}$--», публично демонстрировал атрибутику и символику схожую с нацистской, а именно символ «коловрат». В судебном заседании ФИО6, его законные представители ФИО2 и ФИОЗ в содеянном раскаялись, указали, что сын не знал значение изображения, не желал его публичной демонстрации. Представители МВД по РТ в судебном заседании пояснили суду, что ФИО6 на своей странице в сети Интернет на сайте « $\mathrm{N}$--», публично демонстрировал атрибутику и символику схожую с нацистской, а именно символ «коловрат». Страница ... находилась в общем доступе...11

В приведенных выше ситуациях возникает прямая конкуренция между ст. 354.1 УК РФ и ст. 20.3 КоАП РФ. При этом практика применения ст. 20.3 КоАП РФ является достаточно устоявшейся, что в определенной мере осложняет наработку практики применения ст. 354.1 УК РФ.

Представляется правильным, что в связи с принятием ст. 354.1 УК РФ из диспозиций ч. 1 и 2 ст. 20.3 КоАП РФ должно быть исключено указание на публичную пропаганду или демонстрирование нацистской атрибутики и символики, т.к. эти действия вполне способны образовать состав преступления, предусмотренный ч. 1 ст. 354.1 УК РФ.

Резюмируя сказанное, хотелось бы надеяться, что судебно-следственные органы в ближайшее время наработают единообразную практику применения положений УК РФ и КоАП РФ в данной сфере, в результате чего наиболее опасные проявления экстремизма, в том числе реабилитация нацизма будут неотвратимо влечь уголовную ответственность лиц, их совершивших.

\section{Библиография}

Administrativnoe delo № 5-493/2014, Arhiv Laiševskogo rajonnogo suda Respubliki Tatarstan. $2014 \mathrm{~g}$.

Administrativnoe delo № 5-137/2015, Arhiv Novo-Savinovskogo rajonnogo suda g. Kazani Respubliki Tatarstan. $2015 \mathrm{~g}$.

Edinyj federal'nyj spisok organizacij, v tom čisle inostrannyh i meždunarodnyh organizacij, priznannyh v sootvetstvii s zakonodatel'stvom Rossijskoj Federacii terrorističeskimi. Federal'naâ služba bezopasnosti Rossijskoj Federacii) http://www.fsb.ru/fsb/npd/terror.htm. Graždanskoe delo № 3-129/2015, Arhiv Krasnoârskogo kraevogo suda. 2015 g. Ugolovnoe delo № 1-25/2015, Arhiv Verhovnogo Suda Respubliki Krym. 2015 g. Ugolovnoe delo № 1-34/2016, Arhiv Verhovnogo suda Respubliki Burâtiâ. 2016 g. Ugolovnoe delo № 2-34/2016, Arhiv Stavropol'skogo kraevogo suda. 2016 g.

Ugolovnoe delo № ot 2.08.2017 po delu № 1-18/2017, Arhiv Verhovnogo Suda Respubliki Krym. $2017 \mathrm{~g}$.

11 Административное дело № 5-137/2015, Архив Ново-Савиновского районного суда г. Казани Республики Татарстан. 2015 г. (Administrativnoe delo № 5-137/2015, Arhiv Novo-Savinovskogo rajonnogo suda g. Kazani Respubliki Tatarstan. 2015 g.).

Prawo 327, 2019

(C) for this edition by CNS 


\title{
Rehabilitation of Nazism as a manifestation of extremism: Issues of qualification in criminal and administrative law of the Russian Federation
}

\begin{abstract}
Summary
The article is devoted to the issues of qualifying actions related to the rehabilitation of Nazism under the Criminal Code of the Russian Federation as manifestations of extremism. The issues of the formation of the practice of application of art. 354.1 of the Criminal Code of the Russian Federation are being analyzed, as well as the delimitation of the rehabilitation of Nazism from related crimes and administrative offenses.
\end{abstract}

Keywords: extremist activity, terrorist organization, extremist organization, Nazism, rehabilitation of Nazism. 